Supplement of Biogeosciences, 17, 3317-3341, 2020

https://doi.org/10.5194/bg-17-3317-2020-supplement

(C) Author(s) 2020. This work is distributed under

the Creative Commons Attribution 4.0 License.

(c) (1)

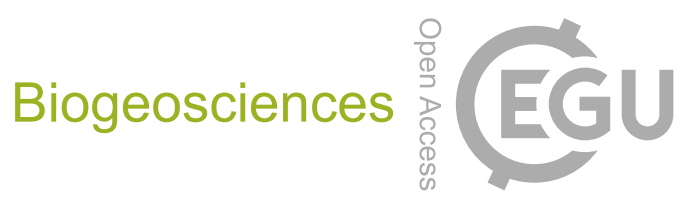

Supplement of

\title{
Physical and biogeochemical impacts of RCP8.5 scenario in the Peru up- welling system
}

Vincent Echevin et al.

Correspondence to: Vincent Echevin (vincent.echevin@ird.fr)

The copyright of individual parts of the supplement might differ from the CC BY 4.0 License. 


\section{Temperature $\left[{ }^{\circ} \mathrm{C}\right]$}

a)

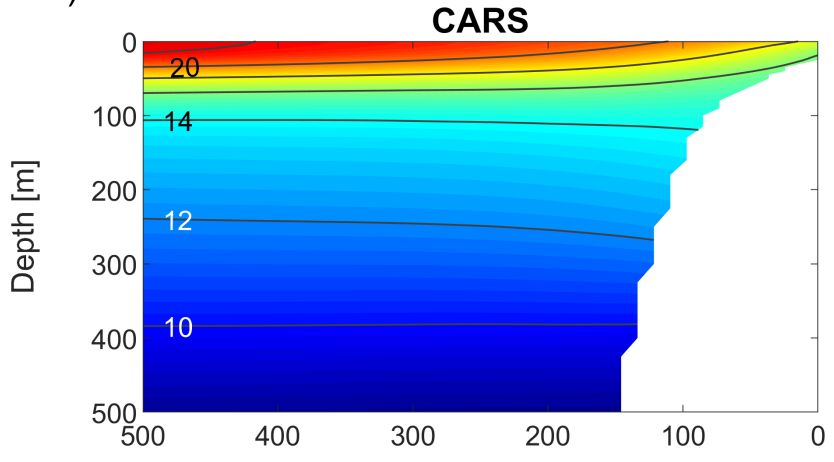

b)

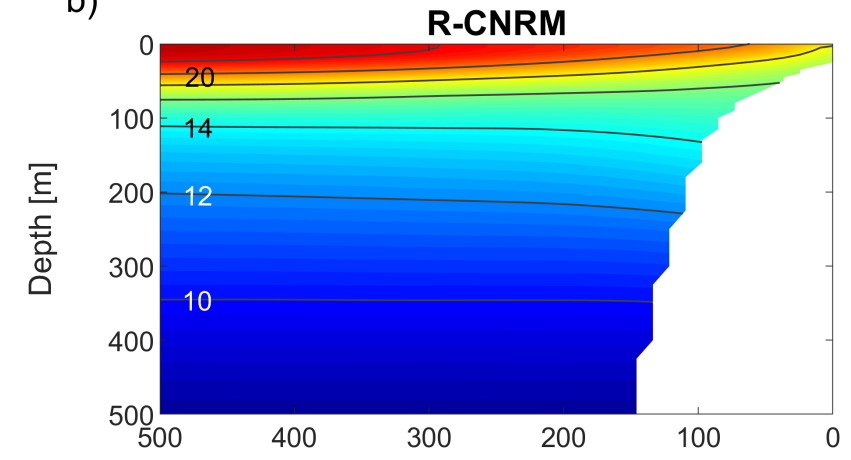

c)

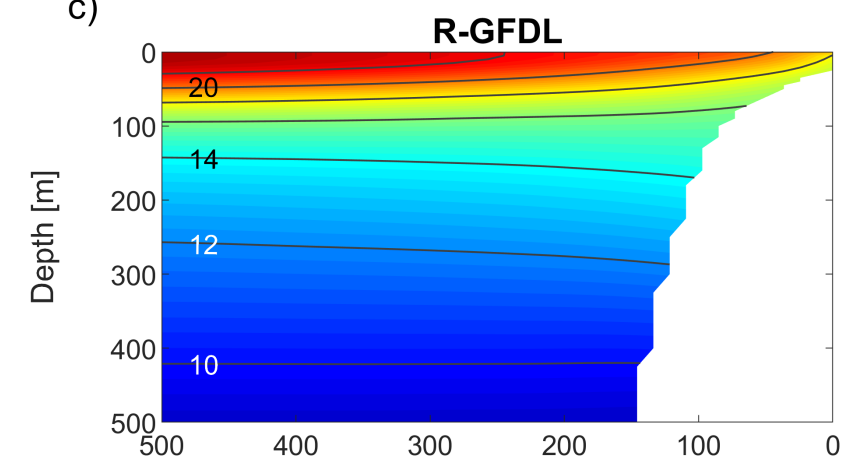

d)

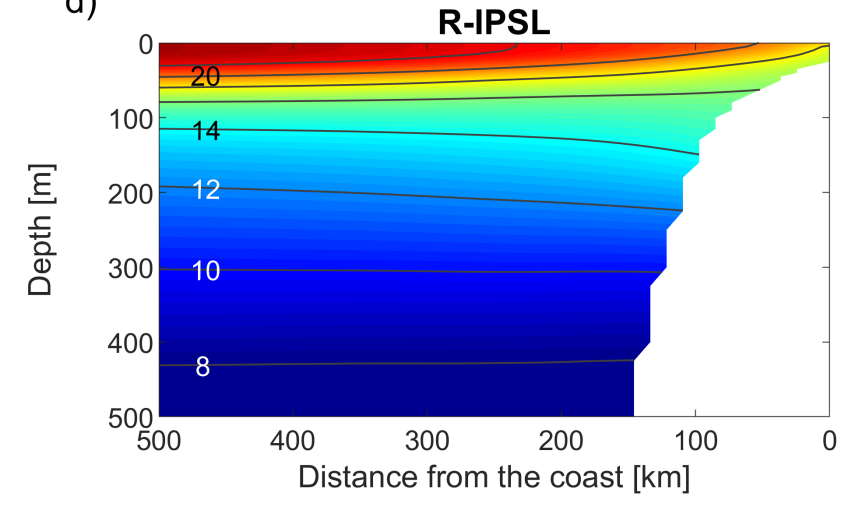

Oxygen [ $\mu \mathrm{mol} / \mathrm{L}]$

e)
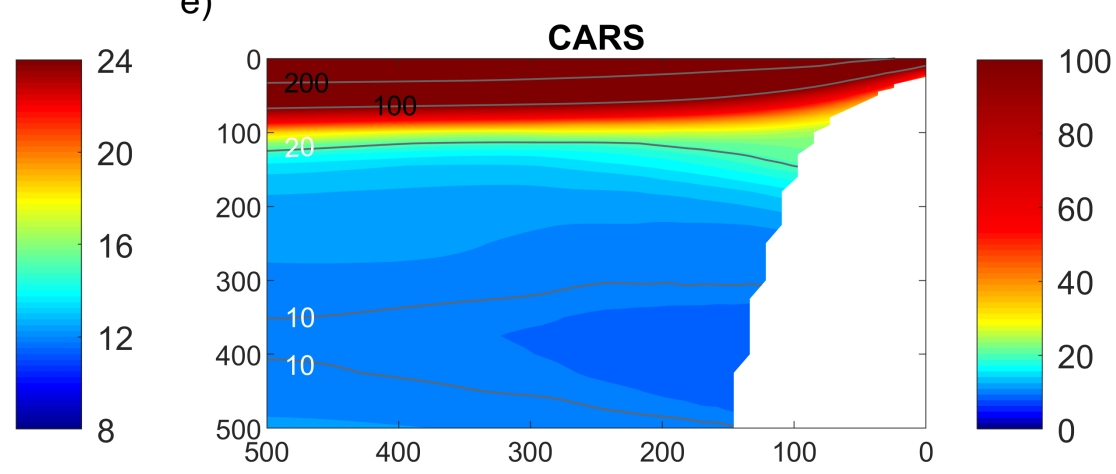

f)

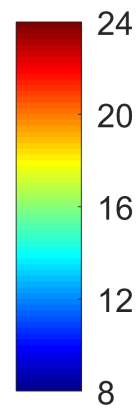

(1)
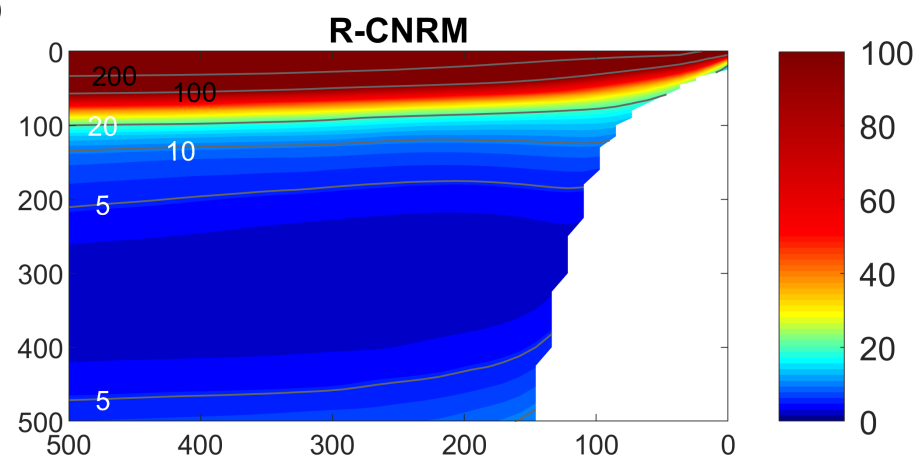

g)

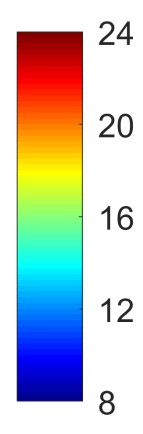

g)
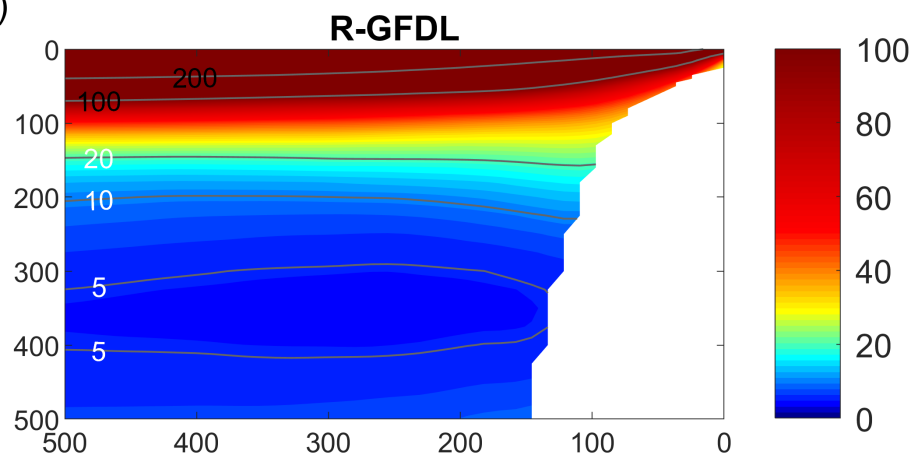

h)

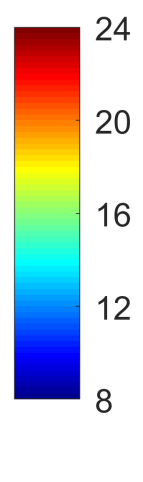

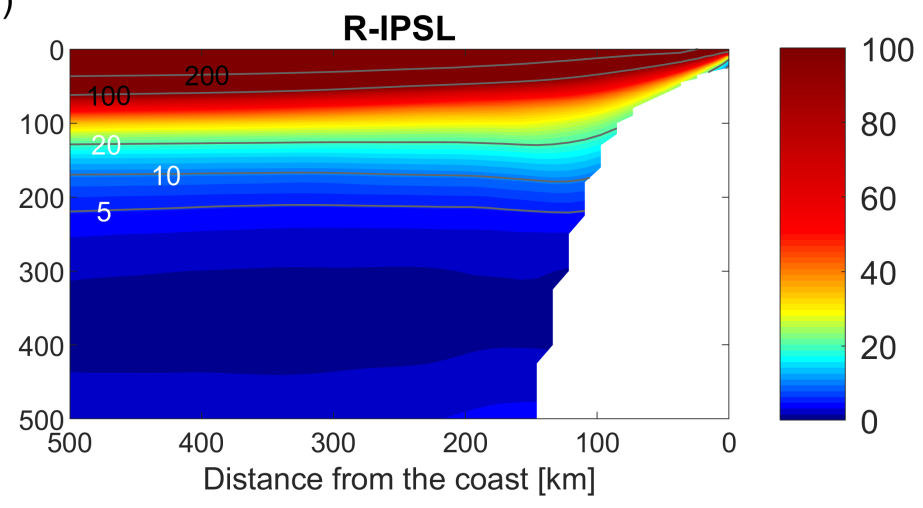

Figure S1: Annual vertical sections of (a),(b),(c),(d) nearshore temperature and (e),(f),(g),(h) nearshore oxygen for (a),(e) CARS, (b),(f) R-CNRM, (c),(g) R-GFDL and (d),(h) R-IPSL. They are alongshore averaged between $7^{\circ} \mathrm{S}$ and $13^{\circ} \mathrm{S}$, and from 2006 to 2015. 


\section{Temperature $\left[{ }^{\circ} \mathrm{C}\right]$}

a)
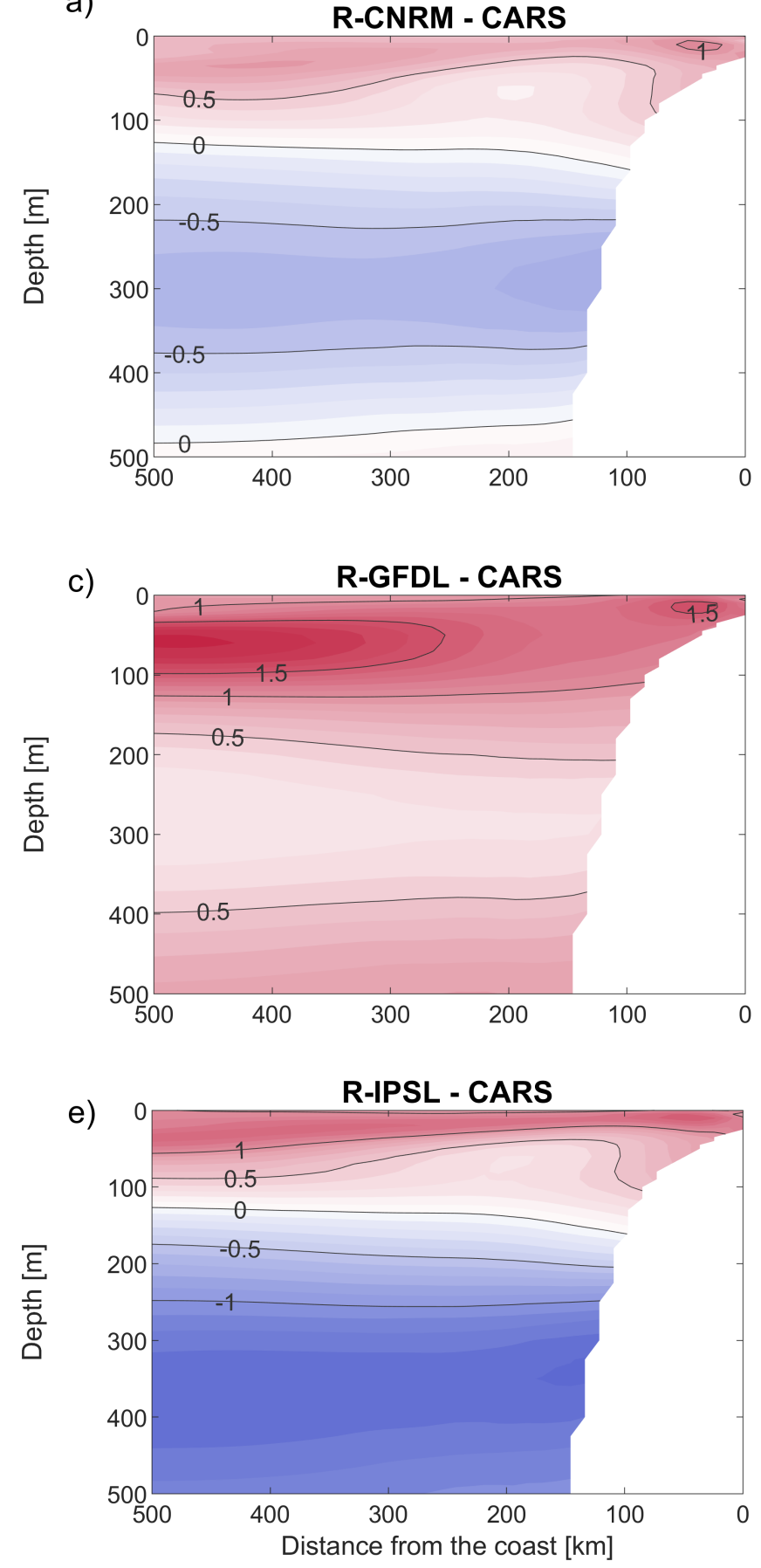

Oxygen [ $\mu \mathrm{mol} / \mathrm{L}]$

b)

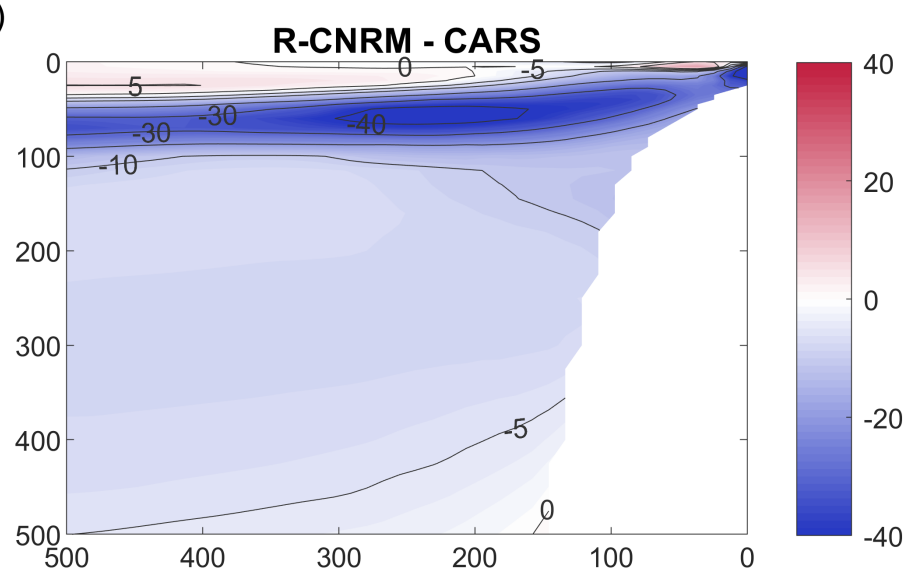

d)
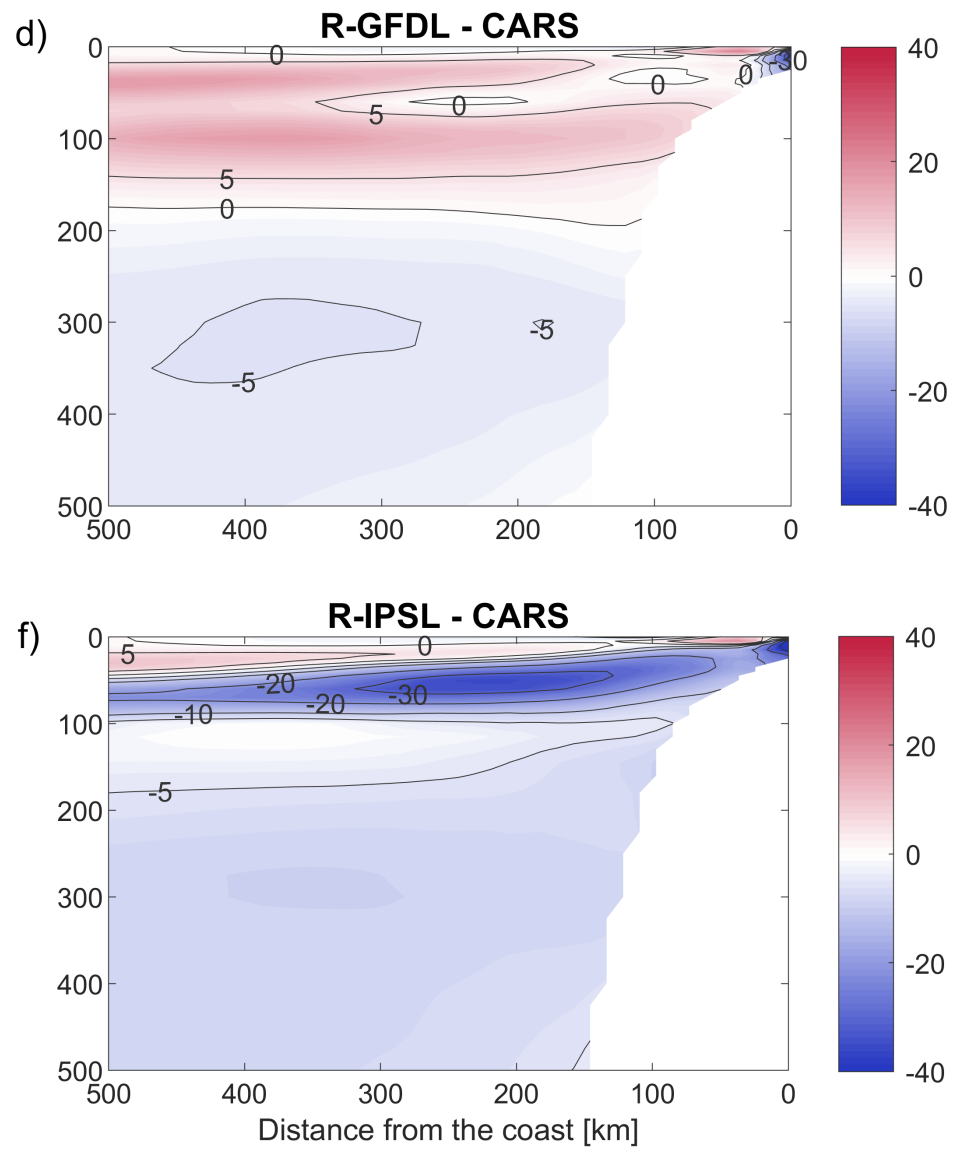

Figure S2: Annual vertical sections of bias of (a),(b),(c),(d) nearshore temperature and (e),(f),(g),(h) nearshore oxygen. The differences are calculated between (a),(d) R-CNRM and CARS, (b),(e) R-GFDL and CARS and (c),(f) R-IPSL and CARS. They are alongshore averaged between $7^{\circ} \mathrm{S}$ and $13^{\circ} \mathrm{S}$, and from 2006 to 2015 . 